\title{
Caracterización geoedáfica del Valle de Secastilla, Huesca (España)
}

D. Badía ${ }^{1}$, J.A. Cuchí ${ }^{1}$, J. Casanova ${ }^{1}$, C. Martí ${ }^{1}$, J. Ferrer $^{2}$, J. Albar ${ }^{2}$

${ }^{1}$ Escuela Politécnica Superior de Huesca. Universidad de Zaragoza. Correo: jcasan@unizar.es

${ }^{2}$ Viñas del Vero S.A.

\section{Introducción}

Secastilla se sitúa en el NE de la Península Ibérica, entre los Pirineos y el Valle del Ebro. Es una población perteneciente a la Denominación de Origen Somontano, localizada en el interfluvio Cinca-Ésera.

Los suelos muestreados se disponen en una ladera (figura 1), entre los barrancos de Pallaruelo y Peralta (Secastilla, D.O. Somontano).

\section{Material y métodos}

Seleccionados los perfiles de suelos más representativos, se describen macromorfológicamente (FAO, 2009) y se muestrean para su análisis. De la fracción de tierra fina, se analizan sus principales propiedades físicas y químicas $(\mathrm{pH}$, carbonatos, materia orgánica, $\mathrm{CEe}$, iones en solución, porosidad, estabilidad estructural, CRAD, granulometría, CIC), se clasifican (IUSS, 2007) y se evalúa el potencial de vigor y de precocidad del terreno para la viña (Morlat, 2010).

\section{Resultados}

Dentro de un mismo contexto climático, las variaciones litológicas y del relieve conducen a la formación de diferentes tipos de suelos (figura 2).

1- Calcilutitas o margas en laderas. En estas condiciones se desarrollan Calcisoles háplicos.

2- Conglomerados en laderas convexas y cerros. Presentan Regosoles lépticos.

3- Conglomerados superpuestos a calcilutitas en laderas. Se clasifican como Regosoles háplicos.

4- Arcillas con yesos en laderas y rellenos. Se clasifican como Gipsisoles háplicos.

5- Depósitos coluviales. Se trata de Regosoles colúvicos.

6- Depósitos aluviales. Son Fluvisoles háplicos 


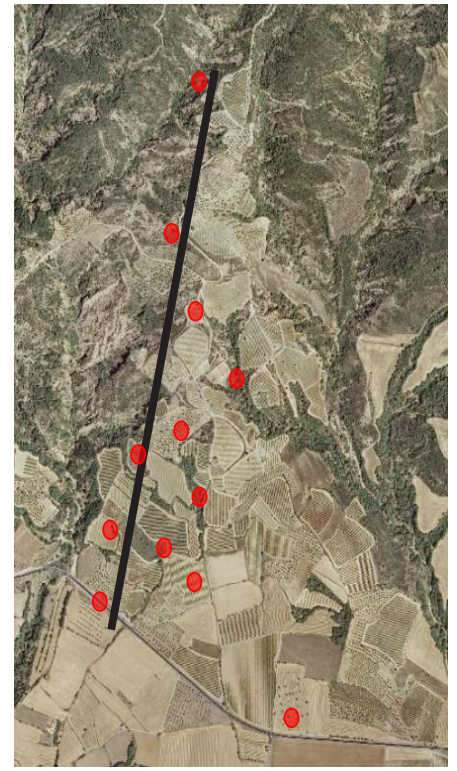

Figura 1Transecto de los perfiles caracterizados en Secastilla (DO Somontano)

Conglomerados con calcilutitas Keuper Coluvio

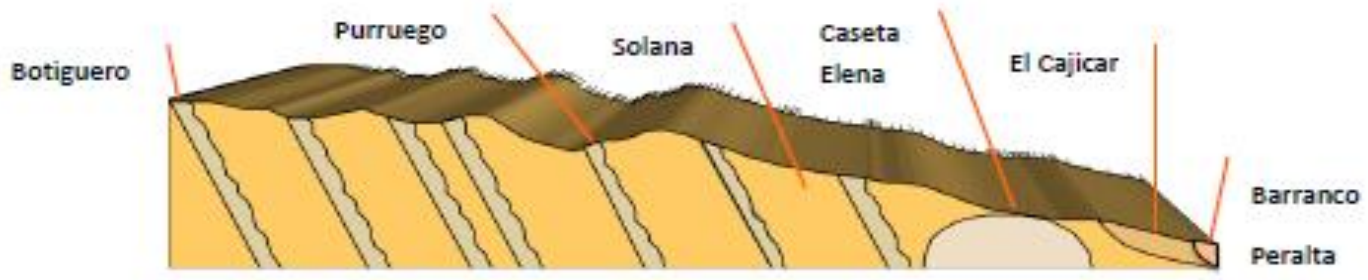

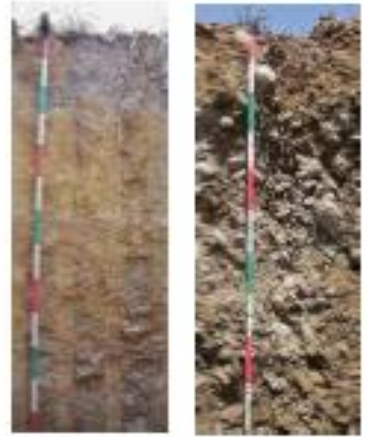

Lutitas

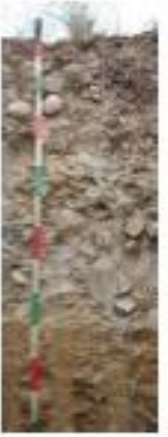

Conglo- Arcillas y

merado yesos y Lutitas
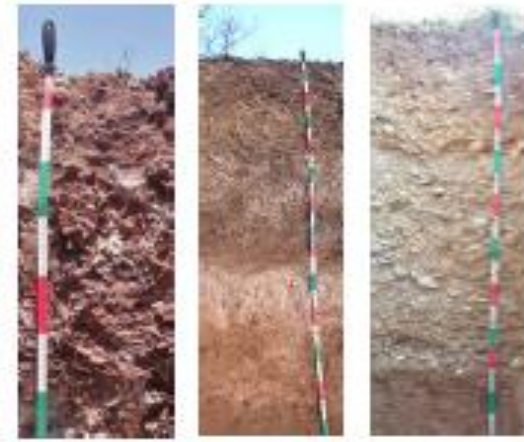

Deposito Depósito

rados coluvial

aluvial

Figura 2: Tipos de suelos formados por la influencia del relieve y las variaciones litológicas en Secastilla (DO Somontano)

\section{Conclusiones}

Cada suelo posee unas propiedades y componentes (CRAD, caliza activa, pedregosidad, espesor...) con influencia sobre el potencial de vigor y precocidad del viñedo y, en definitiva, sobre la calidad del vino

\section{Bibliografía}


FAO (2009) Guía para la descripción de suelos. FAO, Roma

IUSS Grupo de Trabajo WRB. (2007). Base Referencial Mundial del Recurso Suelo. Primera actualización 2007. Informes sobre Recursos Mundiales de Suelos No. 103. FAO, Roma.

Morlat, R. (2010). Traité de viticulture de terroir. Editions Tec\&Doc 